\title{
The Proportionate Development of Partial Embryos.
}

\author{
By \\ T. H. Morgan. \\ With 1 figure in text. \\ Eingegangen am 16. Angust 1901.
}

I.

In connection with the problems of regeneration one of the first questions that is likely to oceur to any one who has followed the modern cytological movement is the question of the relation of the cells in the old and new parts. The problem is especially interesting in those cases in which the old part is entirely changed over into a new, whole organism of smaller size. We naturally ask whether the smaller organism has cells that are correspondingly small, or whether it makes use of the same sized elements as does the full-grown form? In those cases in which the new part is produced in the new tissue appearing at the cut-end the origin of the new cells and their relation to those in the old part have often excited the interest of students of regeneration; but the former cases in which the old part changes over entirely into the new part has up to the present time been almost entirely neglected.

In this same connection some important questions arise as to the method of development of whole embryos from $1 / 2$ and $1 / 4$ blastomeres. Are these embryos in reality miniature copies of the entire embryo, or are they only miniatures in form? If all the cells of which the embryo is composed are also reduced in size, we should expect to find the number of cells present in the small embryos the same as in the whole embryos, and the embryos would be in reality proportionate copies of the whole embryo. If, however, the number of cells is less in the small, whole embryos, then they are only copies of the entire embryos so far as their form is concerned, and 
important questions at once arise as to the value of the cells as building material of the embryo.

I attempted to find an answer to these questions in 1894, for previous to that time these problems had not been specially considered. It was found that the isolated $1 / 2$ blastula of the sea-urchin's egg divided exactly the same number of times that it would have done had it remained in contact with its fellow, and produced a blastula containing half the number of cells characteristic of the whole blastula, and although the development of the half-blastula was often many hours delayed, yet it never made the entire number of cells, although this would have been the case had each cell divided only once more. The isolated $1 / 4$ blastomere produced also about a fourth the number of cells found in the whole blastula, and the $1 / \mathrm{s}$ blastomere produced about an eighth the total number. In the case of the $1 / 4$ and $1 / 3$ blastulae the gastrula stage may not appear althongh the blastula may remain alive, and in apparently a healthy condition for several days; and even in those cases in which an older stage is produced it appears later than in the normal whole embryo, and during the interval the cells may increase somewhat in number, so that there may be present more than a fourth or an eighth of the total number. The general result is, however, clear that at the end of the cleavage period the isolated blastomere makes only a half, or a fourth, or an eighth of the number of cells present in the whole embryo. I concluded from my experiment that the small embryos are not perfect miniature copies of the whole embryo, in as much as the size of the cells in the $1 / 2$ embryo is the same as in the normal and, therefore, twice too large in proportion to the size of the embryo. In the $1 / 4$ embryo the cells are four times too large, and in the $1 / 8$ embryo eight times too large in comparison with the normal embryo.

We have come to look upon the cells as the units, or building blocks, of which the embryo is made, and the further question arises, as to how these "partial embryos " proceed to build up their organs with elements twice or four or even eight times larger, in proportion to the size of the small embryo, than in the normal larva.

To settle this question I selected one organ, the archenteron -

1) The only statement that had been made before $I$ began my work was one by Drresce to the effect that the half-blastula appeared to have half the number of cells that the whole blastula contains. ZoJA had also in 1891 described the number of cells in partial embryos of medusae. 
or embryonic digestive tract - since it is the first ${ }^{1}$ ) organ that develops out of the blastula, and by counting the number of cells in the archenteron of the whole and of the spartial * embryos I attempted to find out if the smaller embryo makes use of the same number of cells as does the whole embryo, or of only half as many, etc. If the first method is adopted, then as the cells in the archenteron are as many and as large as in the full-sized embryo the digestive tract must also be as large, and it will be relatively twice too large for the rest of the body, and hence the embryo will not be a miniature copy of the whole embryo. If the other alternative is followed, then one half the number of cells characteristic of the entire embryo will produce an archenteron of the same relative size, although the cells will be relatively twice too large. The results of a large number of counts that I made of the cells in the archenteron of the small embryos seemed to show that the number turned in was generally greater in the $1 / 2$ embryo than half the entire number and greater in the $1 / 4$ embryo than one-fourth the whole number. I concluded that the small embryo tended to use the same number of cells to produce its organs that is characteristic of the entire embryo. There are several considerations that make this conclusion of doubtful value; for instance, a), the delay in the development may make it possible for the cells in that part of the wall from which the archenteron will form to increase more rapidly in number as they turn in, than do the cells in the normal embryo, and if so, while their number would be larger for a given stage, the cells themselves would be smaller; b), there is no exact moment at which the gastrulation can be said to be completed unless we choose some such arbitrary limit as the formation of the gut-ponches, or the contact of the inner end of the archenteron with the stomodaeum, hence there is a difficulty in comparing identical stages, although this can be done approximately; c), lastly great variability was found to exist in the actual number of cells turned in to form the archenteron, although the highest numbers agreed with that characteristic of the entire embryo.

My conclusion that the number of cells in the archenteron in the smaller embryos was proportionately larger, and approximated to that in the entire embryo seemed to be supported also by the observation that very often the number of cells in archentera that were

1) Excepting the mesenchyme which however only forms a skeleton at a later stage. 
not even completely finished was nearly the normal number and much greater than half the number; and moreover in many cases the archenteron was much larger in proportion to the rest of the body in the small embryo than in the normal one.

Previously I bad examined the number of cells in the $1 / 2$ embryo of a teleost - Fundulus -, and had found also evidence that the number of cells characteristic of the adult went to form the eye, nerve cord, ete., of the $1 / 2$ embryo. Later I examined the number of cells in embryos of Amphioxus that had developed from isolated $1 / 2$ and $1 / 4$ blastomeres. In these the total number of cells in the $1 / 2$ embryo was found to be half of the number ${ }^{1}$ ) in the normal embryo, and in the $1 / 4$ embryo one fourth the total number. Crosssections of these embryos seemed to show that more than two-thirds the normal number of cells were present in cross-sections in some of the organs of the $1 / 2$ embryo, and more than one half to make the organs of the $1 / 4$ embryo.

The results of my study of the number of cells invaginated by whole and partial embryos of Sphaerechinus showed as stated above that a proportionately larger number are turned in by the smaller embryos. The whole embryo of Sphaerechinus contains somewhat over 500 cells in the wall of the blastula, and, of these, 50 cells are invaginated to make the archenteron.

In a very small embryo, from an egg-fragment, containing only 57 nuclei in the outer wall, there were 22 nuclei in the archenteron, in another, with 56 nuclei in the outer wall, there were 36 nuclei in the archenteron. If these embryos had turned in only one-tenth the entire number present in the blastula they would have used only eight to ten cells, but the results show, that about twice as many in one case, and three times as many in the other were invaginated.

Another embryo of Sphaerechinus derived from a $1 / \mathrm{s}$ blastomere had 79 cells in the wall and turned in 20 to 25 in the arehenteron which at the time was only about two-thirds completed. If the proportionate number had been invaginated only ten cells would have been used to form the entire archenteron. Another embryo that developed from a fragment of the blastula wall contained only 31

1) Throngh an unfortunate mistake or error the number of cells given (on page 379 of my paper) for the $1 / 2$ larva was too great, although the data given show the number of cells to have been one half the total number. Drisch has also called attention to this error. 
cells in the wall, but turned in 12 cells to make the archenteron. The proportionate number would have been four cells.

ZoJA published first in 1891, and more fully in 1895 the resuits of a study of the development of isolated blastomeres of certain medusae. He found in Clytia and Laodice that the endoderm of the $1 / 2$ embryo begins to form when only half as many cells are present as are present in the whole embryo at this period. The number of endodermal cells was not determined. On the other hand in Liriope (in which the endoderm is delaminated in the whole embryo when 16 -cells are present) the $1 / 2$ embryo does not delaminate at its 8 -cell stage, but only when sixteen cells have been formed, i. e., the number of cells is the same as in the whole embryo, and the number of endoderm cells is also the total number. The same relation probably holds for the $1 / 4$ embryo, and also for the $1 / 4$ embryo of Geryonia. ZoJA thought that in these cases the isolated cell returns to the condition of the ovum, or possibly the presence of a large segmentation eavity in the early stages of development in Clytia and Laodice makes it possible to invaginate the endoderm, while in liriope and Geryonia the smallness of the segmentation cavity in the $1 / 2$ and $1 / 4$ larvae determines that the karyokinetic spindle shall assume once or twice more a tangential position, so that more superficial cells are produced. A larger segmentation cavity developes; and in consequenee a delamination of the endoderm may then take place.

HerLitzka in 1897 compared the size of certain organs in the $1 / 2$ embryo of Triton with those of the whole embryo. He found that the nervous system and the notochord are the same size in both cases, while the intestine, and the myotomes of the $1 / 2$ embryo are smaller in cross-section, especially the former, than in the whole embryo. In regard to the number of cells in these organs he found that the number of cells in cross-sections of the spinal cord is the same in the $1 / 2$ embryo and in the whole embryo, but in the myotomes the number in the $1 / 2$ embryo is just half that of the whole embryo.

DRIESCH has more recently taken up the same problem, and finds that while my conclusion in regard to the number of cells formed by the small embryos is correct, yet in regard to the number of cells that go to form the different organs of the body he has obtained different results. He finds that the small embryos use the same proportionate number of cells as do the whole embryos, i. e., 
the $1 / 2$ embryo having half the number of cells characteristic of the whole embryo uses half as many cells to form each organ as does the normal embryo, and while the cells are, of course, twice too large, as I had shown, yet the organs in the small larva bear the same relative size to the rest of the body as in the whole embryo.

After the publication of DRIESCH's first paper I collected new material of the $1 / 2$ embryos of Fundulus, prepared new series of embryos of Amphioxus, and looked over again my preparations of the "partial " embryos of the sea-urchin. I can, therefore, give here, for the first time, the results of this reëxamination of the material, and in the light of DrIEScr's conclusions and criticism give the questions a fuller consideration.

In my former study of the number of cells in the $1 / 2$ embryo of the teleost, Fundulus, I found that the number of cells in crosssections of the eye-vesicles, and of the nerve-cord and notochord was about the same in the half and in the whole embryos. An examination of new material ${ }^{1}$ ) shows that there is much difference in the sizes of the $1 / 2$ embryos. Some of the embryos are long and narrow, others are shorter and thicker. The difference may be due to the different rate of growth over the yolk-sphere, as well as to other differences in the embryos themselves. Correspondingly there is some variability in the number of cells in cross-sections of the embryos at the same stage of development. The results show that in some of the $1 / 2$ embryos the number of cells in cross-sections is the same as in whole embryos of the same stage; but the total number of cells is always less in the $1 / 2$ embryos since they are shorter 2$)$. Other $1 / 2$ embryos contain fewer cells in cross-section than do whole embryos. The results, therefore, are not constant, although the sections show more often an approximate agreement in the number of cells in cross-sections of the $1 / 2$ embryos and whole embryos. It should in fairness be stated that my reëxamination has shown that the teleost embryo is an unfavorable object on which to base a comparison between the half and whole development for the following reasons. In the first place there is a peculiarity in the development of the fish-embryo that may make the problem more complicated. It is known that protoplasm from the yolk-sphere continues to flow

1) Collected in ' 97.

2) Those that are nearly as long as the whole embryo are as a rule much narrower. 
into the blastoderm during the early cleavage period. Therefore in removing one of the two blastomeres we may not remove half of the formative protoplasm, and if some of that that would have gone into the cell removed, or into its descendants should now go into the remaining blastomere the latter will contain more than half of the protoplasm, and theoretically at least would then be in a position to produce a larger number of cells than half the whole number. Another difficulty lies in the size of the yolk-sphere that is overgrown by the blastoderm. It is the same size for both half and whole embryos, and since the former has less material at the start, but the same area to cover, the two embryos do not, in one sense, stand in the relation of half and whole organisms. Finally the method of formation of the fish-embryo from the blastoderm is such, that at first there is present more material than is actually used up in the formation of the anterior end of the embryo, - the excess being carried posteriorly in the tail-knob. Under these conditions it is possible that when the anterior end of the embryo is formed it may, in the case of the $1 / 2$ embryo, use up relatively more of the material than half the amount, and leave less for the formation of the posterior end of the embryo, which may be, however, compensated for by a shorter embryo forming. The delay in the development must also be taken into account.

For these reasons it seems to me that it will be difficult to find a decisive answer to the general problem of the number of cells from a study of the fish embryo, although of course the special problems that are found here are none the less important in themselves.

In regard to Amphioxus a new series of preparations has served to verify the results given in my paper dealing with the number of cells in larvae from isolated blastomeres of this animal. There are, however, some mistakes in the paper, and some statements that are confusing ${ }^{1}$. The total number of cells in cross-sections of the $1 / 2$ larva is about two-thirds of the number in cross-sections of the whole larva; and since the $1 / 2$ larva is about two-thirds as long as the whole larva the total number of cells is $4 / 9$ or about $1 / 2$ that of the

1) Particularly where the number of cells in cross-sections is spoken of as more than half but not the whole number. If proportionate embryos are formed two-thirds the total number of cells should be expected in crosssections. 
whole larva ${ }^{1}$. The number of cells in cross-sections of the $1 / 4$ larva is about one half the number in cross-sections of the whole larva; and since each larva is about one half as long as the entire larva the total number of cells is about one fourth. The results show that the isolated blastomere produces small larvae that are miniature copies in form of the whole larva. The larvae are proportionate larva that have in the cross-sections of several organs two-thirds and one-half respectively of the total number of cells as the theory demands. The somewhat larger number of cells in the small larrae may be due to the longer time necessary for them to reach a given stage.

In certain organs of the body, however, the results have shown that the total number of cells is present in cross-sections of the small larvae. The notochord and the nerve-chord contain as many cells in cross-section in the small larvae as in the whole ones, and these organs have about the same area in both eases. The number of cells that pinch off from the archenteron in the whole larva to form the notochord is about three in any cross-section. If the $1 / 2$ larva used proportionately as many cells it would have only two cells in cross-section, and the $1 / 4$ larva only $1 \frac{1 / 2}{2}$ cells. It may be claimed that these numbers come within the range of error of counting, and this may be granted; but since the outline of the notochord is as large in the $1 / 4$ larva as in the whole larva, this supports strongly the view that the number of cells is really the same. The same arguments apply to the number of cells in the nervous system, but with less force since it is more difficult to count the cells in this case. It is interesting in this connection to find that HerLImzJxA found in Triton that the notochord and nerve-cord contain as many cells in the $1 / 2$ embryo as in the whole.

Returaing once more to the question of the number of cells invaginated to form the archenteron of the sea-urchin $I$ concluded, as has been said, that proportionately more cells are turned in by the smaller embryos, and since in many cases the total number of cells invaginated was equal to the number present in the whole embryo I stated that there is a tendency to use the whole number 2 ).

1) Not $\% / 3$ as stated by an error in $\mathrm{my}$ former paper in which, however, the correct number of cells for each cross-section is given, as well as the correct length of the larva.

2) Drresch has objected to the use of this word, tendency, as obscure, 
DRIESCH, in a criticism of my results, has pointed out that my tables show no constancy between the actual number of cells in the small embryos, and the number invaginated. This criticism is just, and is obvious on only a casual examination of the tables, and I was fully aware of it, but I do not think that we need infer from this that my conclusion is necessarily wrong. I pointed out explicitely that there are obvious reasons for differences of this kind, since I counted the nuelei in all the small larvae that $I$ found, and did not attempt to discriminate amongst them. It is well known that in many cases embryos from isolated $1 / 2$ and $1 / 1$ embryos do not gastrulate at all, and in nearly all eases their development is delayed. I also pointed out that it is not improbable that in some of the cases given the number of cells in the archenteron had increased in number after gastrulating. Some of the estimates are from embryos that have not finished gastrulating, and some of the embryos may have been abnormal. I made allowances for all these possibilities, and still the residuum seemed to show that the number of cells is, in most cases, too large.

It was with some interest that I reëxamined my preparations while in a frame of mind that would have lead me to accept DrIesch's conclusion as the simplest solution of the problem. Again, however, I was impressed by the large number of cells present in the small embryos, especially in the rery small ones, - a number out of all proportion to the anticipated number, i. e., out of all proportion to the number of cells in the outer wall. How then can we harmonize these results? The fact that there are more cells present is easily demonstrated. Shall we regard those cases in which the small embryo has more or less nearly its proportionate number of cells in the archenteron as normal cases and account for the others as abnormal? I doubt if this would be a satisfactory solntion of the difficulty, since it begs the entire question at the start. Can we get out of the dilemma by supposing that in one organ - the mesenchyme - a proportionate number of cells is used, and in another organ a number of cells that is proportionately larger than in the whole embryo? Herutaka's results might give some support to this view, for he found that the different organs behave

but it is clear, I think, from the context of my paper that I meant proportionately too many cells are invaginated by the small embryos and in many cases as many as in the whole embryo. 
differently in regard to the total number of cells in the same embryo. I doubt, however, if this solution would be entirely satisfactory.

There is a further suggestion that may account in part for the larger number of invaginated cells in the small larva, viz., the delay that takes place in the gastrulation of the smaller pieces. There are some facts that seem to support this conclusion. The larger partial embryos gastrulate sooner than do the smaller ones, and in many cases the disproportion in the number of cells turned in is less than in the smaller embryos, i. e., although they may more often have the whole number, yet this represents a smaller proportionate increase than that found in the small embryos. Further it is by no means improbable that after a long delay the cells in the endodermal plate of the small larvae may begin to divide and then gastrulate. The cells turned in correspond, therefore, to a relatively smaller number of cells in the blastula wall. This process would be different from that which takes place in the normal embryo, and while accounting for the larger number of cells in the small embryo, it also shows, at the same time, that they may come from a proportionate number of cells of the blastula.

That this hypothesis does not give a completely satisfactory solution of the difference is found in an examination of the size of the archenteron in the very small embryos. In the figures that I have given it will be easily seen that the archenteron is often very much too large for the size of the piece. There can be no doubt that many of the very small embryos present this characteristic. This condition would not exist if the gastrulation took place by the later division of a proportionate number of cells in the endodermal plate of the smaller embryo.

Closely connected with the questions relating to the number of cells in embryos from isolated blastomeres are those relating to the method of development of embryos from fragments of the unsegmented egg. The two problems are by no means necessarily identical, or at least we could not have assumed them to be so on a priori grounds, since we had no evidence to decide whether the whole nucleus of an egg fragment would rua through the same number of division characteristic of the undivided egg, or whether the number of division would be in proportion to, and limited by the amount of protoplasm contained in the fragment.

The results of my examination of the development of fragments 
of the egg of the sea-urchin showed that the larger pieces divided oftener than the small ones, although both contained the same kind of nucleus, hence the conclusion is obvious that the number of divisions of the segmentation nucleus is determined by the volume of the protoplasm, and there is no predetermined number of divisions that is fixed for the nucleus itself, but the relation of the nucleus to the volume of the protoplasm determines how often the nuclens may divide. The result shows that the $1 / 2$ blastomere produces only half the number of cells that the whole egg produces, because it contains only half as much protoplasm and not because there is a fixed number of divisions for the segmentation nucleus. I may point out that this result presents great difficulties for those who believe the division of the nucleus is a process of umravelling of the qualities of the embryo, since the same result - the formation of an embryo - may be brought about by a piece that produces only an eighth as many divisions as does the normal egg.

It was found that the smallest pieces that produce gastrulae contain from 50 to 75 cells while the normal number of cells is, in a whole embryo on the point gastrulating, about 500. The smallest pieces correspond, therefore, to about $1 / 5$ to $1 / 10$ the volume of the entire egg, to judge from the relative number of cells, and this result corresponds to that obtained from isolated blastomeres, in which it is found that the $1 / 8$ blastula is near the lower limit of size to produce the gastrula-stage.

If instead of estimating the relative size of the piece of the egs by the number of nuclei that it forms we compare the actual size of the smallest blastulae that gastrulate with the size of the normal gastrula we find that the smallest pieces are only about $1 / 50$ of the volume of the egg, but as I pointed ont in my paper this comparison is hazardous, since, as observation showed, the small pieces do not enlarge in the same proportion as does the normal embryo, and Driescr has later confirmed this conclusion.

The other calculation, based on the number of cells, that was giren in the same paper, probably represents more nearly the lower limit of the power of these pieces to gastrulate.

A further object of my study of the number of cells in partial larvae was to determine how pieces of the blastula-wall prodnce new embryos. If a piece is cut from, or broken off the wall of the blastula stage of the sea-mrehin at the end of the cleavage period, and subsequently closes in and produces a gastrula and later stages, 
does the number of cells in the piece remain the same as when the piece was separated, or does the number increase to the entire number or increase at all before the next stage in the development - the gastrula stage - is formed? Observations showed that these pieces elose in without producing new cells, and the resulting sphere forms a new whole, and develops into a gastrula without increasing to any extent the number of its cells. The result showed that the cells of the blastula-wall are totipotent, as Driesch had also shown, and that any of them ean produce the archenteron, etc. The result demonstrated further, for the first time, that the lack of power of the smaller isolated blastomeres to form a whole embryo is not connected, as had been suggested with their differentiation, since pieces of much later stages can produce entire embryos, if they are larger than the $1 / 10$ blastomeres. The failure of the latter to produce an embryo is therefore the result of their size, and not of their differentiation since the cells are still totipotent at a much later stage than the 16-cell-stage.

There is another question that is closely related to this one of the number of cells formed by pieces of the egg, or by isolated blastomeres, viz., whether the number of cells produced by large and small eggss of the same animal is the same. My attention was first drawn to this problem in 1897 when I found in a string of toad's eggs some egg's that had not more than half the diameter of the average egg. Unfortunately these small egg's did not develop. An egg having only half the diameter of another egg contains only oneeighth the volume, and, therefore, corresponds to a $1 / \mathrm{s}$ blastomere. The question suggests itself whether a small egg of this sort will develop in the same way that a $1 / 8$ blastomere develops, i. e., produce only one-eighth as many cells as the larger egg, or whether the small egg will develop as a larger one develops, i. e., produce the whole number of cells, each cell being one-eighth as large as in the larger embryos. If the latter method of development is followed, the small egg is organised on a smaller scale.

Unfortunately I have not been able to procure again eggs of the toad as small as those first observed. I have found eggs measuring $39 \times 39 \times 39$, and others in the same lot measuring: $49 \times 49 \times 49$. The smaller egg contains about half the volume of the larger one, and corresponds, therefore, to a $1 / 2$ blastomere. The two kinds of eggs develop at the same rate, and smaller embryos are produced by the smaller eggs. Several embryos of each kind 
were cut into sections at different, but corresponding stages, in the hope of finding out whether the smaller embryo contains as many cells as the larger embryo, etc. It has been so difficult to decide with certainty in regard to this question, that I prefer not to commit myself until I can procure new material in which a greater difference in the sizes of the eggs may make it easier to solve the problem. When it is remembered that a cell having half the volume of another, has a diameter in the ratio of 4 to 5 it will be seen how difficult the problem becomes in an embryo having cells of all sorts of irregular shapes.

It may, perhaps, only lead to further difficulties to bring into this connection the results of other experiments that seem to offer a parallel case. It has been shown that small pieces of the stem of Tubularia, that are shorter than the region from which in larger pieces the hydranth is made, produce smaller hydranths at one end of the piece although not proportionately smaller hydranths. In other words although the hydranth is reduced, it is by no means reduced in proportion to the size of the very small pieces. DRIEscr has found that if short pieces are taken from the region just behind the old hydranth, the entire piece is very often transformed into a hydranth only, or even into only a part of a hydranth. There is a $\gg$ tendeney" in this part of the stem to produce not a proportionate structure, but a larger one in relation to the size of the piece, and I think, we may add, there is a tendency to form the whole-sized strueture or the whole-sized distal part of the hydranth. Since these structures are full-sized they will use proportionately too great a number of cells. This case is, it seems to me, parallel to that of the small embryos.

A somewhat similar result has been found by Peebues in the regeneration of very tiny pieces of Hydra. These pieces do not form the total number of tentacles characteristic of the full-sized hydra, but only one, two, three, or four tentacles. If the tentacle ring had been organized on a proportionately smaller scale we should expect six to eight tentacles to appear of very small size, but as this never happens it looks as though tentacles of only a certain size can be formed and hence there is room for fewer of them, i. e., each uses up too much material, or too many cells of the old part.

These examples are, it is true, from another field, but they show us nevertheless that the problem of the formation of smaller organisms may involve other, quantitative factors, than simply the production 
of proportionate organs of smaller size. I have pointed out that these results seem to indicate that the cells as units play only a secondary part in the moulding of the organs of the metazoon body. The development of the typical form by small embryos having only a half or a fourth the total number of cells points to this conclusion, and the facts discovered by Conkurs, viz., that giants and dwaris are produced not by larger and by smaller cells, but by more or fewer cells, leads to the same conclusion. I need scarcely add that we are not, for this reason, justified in ignoring entirely the cells in studying these processes, for the proportionately enormous size of the cells in the very small larvae may still be an important factor in the development, or lack of development of the embryo. But the main fact seems clear, that the organisation of the metazoon, so far as the formative processes are concerned involves the protoplasm as a whole, and is not the outcome of the action of cells as units, although the individual cells as centers may act as boundaries to the action of the formative forces, i. e., in the production of organs a cell is either entirely involved or not at all.

\section{II.}

The preceding summary was written a year ago, and in order to clear up some of the points that have been discussed it was necessary to obtain new material. During June of the present year I went to Beaufort, N. C., to examine the problem of the number of cells invagination in the embryo of the sea-urehin, Tozopnenstes variegatus. Thanks to the ample opportunities offered by the U. S. Fish Commission I obtained the necessary material. I gladly express my obligations to Prof. H. V. WrLson in charge of the Station for many courtesies extended to me during my stay.

The blastomeres were separated by HERssT's method. The eggs were fertilized, and within two to five minutes afterwards were shaken in a tube until they were freed from the membrane. The eggs, after settling, were thrown into Henssr's calcium-free sea water. They remained in this solution until they had reached the two, four or eight-cell stage. They, were then removed, gently shaken in order to separate the blastomeres and put into normal sea water. In this way, as DRIESch has shown, large numbers of isolated blastomeres can be obtained. The method, I can also attest, is immensely superior 
to the former one of violently shaking the membraneless eggs to separate the blastomeres.

It was erident that in order to settle the difference between my former results and those of DRIESCI it would be necessary to preserve continuous series of embryos of the same lot. I shonld add that I have preserved only the partial embryos that rose to the top of the water, as do the normal embryos. These, as experience has taught me, are much more apt to develop into later stages than are the abnormal embryos that swim around on the bottom. The embryos were killed in a corrosive-acetic solution, stained in OnTH's picro-lithium carmine and mounted in balsam.

In the first series, here chosen for description, the gastrulation was completed in the whole embryos at 11 a. m., and even in some of the $1 / 2$ and the $1 / 4$ embryos, although in only a few of these. The whole embryos had about 955 cells (as indicated by the number of nuclei) in the wall and abont 150 in the archenteron. The $1 / 2$ embryos contained in the archenteron, in five cases, 96, 85, 66 (not finished), 56 (not finished). The $1 / 4$ embryos contained in the archenteron 49,57,40,40 (incomplete). These results show that in the archenteron of the partial embryos these are at this time about a half and a fourth respectively of the number of cells in the archenteron of the whole embryo.

Two hours and a half later the whole embryos have about 180 to 190 cells in the archenteron. The $1 / 2$ embryos, in five counts, $96,85,90,95,77+$, and the $1 / 4$ embryos $60,75,56,63,60,65$ cells in the archenteron.

Three hours later there were, in two counts, 268 and 283 cells in the archenteron of the whole embryo. The $1 / 2$ embryos contained in three counts $148,106,92,105$ cells and the $1 / 4$ embryos contained $70,73,72,70,60,36$ ( $2 / 3$ gastrulated $), 60$ (197 cells in wall), 27 (completely gastrulated with 200 cells in wall), $46(1 / 2$ gastrulated, 192 cells in wall).

These results show that there is a steady increase in the number of cells in the archenteron both in the whole and in the partial embryos. If the number of cells in the archenteron of the whole and of the partial embryos of the same age in point of time is compared it is found that the $1 / 2$ and $1 / 4$ embryos contain about a half and a fourth of the number present in the whole embryo. On the other hand it appears that a relatively larger nnmber of cells is invaginated in some of the partial embryos than in the whole embryos, 
and, moreover, in comparison to the number of cells in the outer wall, the partial embryos, especially in those that gastrulate late, turn in proportionately more cells than are at first turned in by the whole embryos.

There is a further point that should be remembered. A few of the partial embryos gastrulate almost as soon as do the whole embryos and there can not be any doubt that in these the number of cells continues to increase from hour to hour. Embryos of this kind will also appear in the later lots, but nevertheless most of the partial embryos in the later lots represent individuals that have gastrulated later, and since practically all of the partial embryos of the later series have in the archenteron more than a half or a fourth or an eighth of the whole number of cells that is first invaginated in the whole embryo there can be no doubt that these delayed partial embryos turn it at first proportionately a large number of cells. The explanation of this is found in the continuous process of cell division by means of which a somewhat larger number of endodermal cells are present when invagination begins.

A second series of embryos, selected for description, includes earlier stages than the last series. The whole blastula that is about to gastrulate has about 800 cells in the wall (including those that are to be invaginated). The $1 / 2$ blastula contains at this time (830 a. m.) from $350-370$ cells and the $1 / 4$ blastula from $180-218$ cells. These figures show that the partial embryos have respectively a half and a fourth the whole number of cells.

Two hours later gastrulation had taken place in the whole embryos. They were found to have in one case about 1000 cells in the outer wall, and in three cases $117,120,130$ nuclei in the archenteron. Some of the $1 / 2$ embryos that had gastrulated contained in five counts $76,68,76,67,65(2 / 3$ gastrulated $)$ nuclei in the archenteron.

An hour later the number of cells in the wall of the whole gastrula was in one case 1350 with 250 cells in the archenteron, and in another case 1440 with 265 in the archenteron. Others had in the arehenteron $127,180,170,145,176$ eells. The $1 / 2$ gastrulae had 120 (with 463 in the wall), 96, 97, 92, 97, 86 nuclei in the archenteron.

After another hour the number of cells in the wall of one whole gastrula was 1510 cells (with 313 in the archenteron). Other counts gare 290,353 in the archenteron. The $1 / 2$ gastrulae contained at 
this time 112, 134, 140,130, 196 nuclei in the archenteron. The $1 / 4$ gastrolae had just begun to gastrulate and in some of these the archenteron did not seem to have been completed. Four counts gave 33 nuclei in the archenteron (and 240 in the wall). 36 (with 193 in the wall), 50 (with 250 in the wail), 44 (with 214 in the wall).

The results of this second series bear out the conclusions from the first series. Other series were not as good as these in all respects, but so far as they go they give similar results.

Figs. $A-C^{\prime}$.
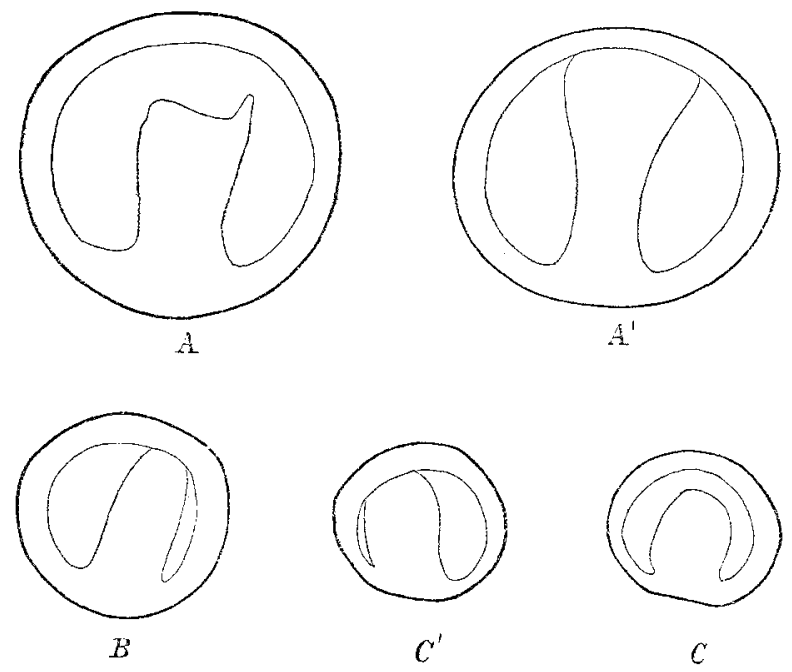

Fig. A. Whole embryo about two-thirds gastrulated. Fig. $A^{i}$. Whole embryo, gastrulation completed. Fig. B. Half-embryo, gastrulation completed. Fig. C. One-fourth embryo. Fig. $C$. One-fonth embryo, shoring excentric archenteron.

A fact that I had formerly observed is very apparent in these new preparations, viz., that the archenteron in most of the partial embryos is proportionately too large for the size of the embryol) and this is especially obvious, as shown in Figs. $A, A^{\prime}, B, C, C^{\prime}$, in the $1 / 2$ and $1 / 4$ embryos. Some of Driesch's figures seem also to me to show the same thing. The result appears to be due in part to the proportionately large number of cells in the archenteron of the smallest partial embryos. The archenteric cells appear to divide oftener

1) One apparent exception to this is given in the first series. In this case the partial embryo appeared to have a proportionately formed digestive tract that contained 27 cells and the wall 200 cells. The numbers bear the ratio characteristic of the whole embryo. 
than the cells in the wall, and if the cells enlarge after each division the larger size of the archenteron in the retarded embryos can be accounted for. The proportionately smaller enlargement of the wall of the partial embryos may also make the difference more apparent.

Another fact that is obvious in all these embryos is that the gastrulation of the $1 / 2$ and $1 / 4$ embryos is quite excentric as shown in Figs. $B, C^{\prime}$. This excentricity may be easily overlooked since the side towards which the archenteron turns, being heavier, is generally turned away from the observer looking at the embryos from above, Fig. $C$, but if the embryos are rotated the excentric position of the archenteron is readily detected, Fig. $C^{\prime}$. Thus the partial embryos are not at first simply whole embryos of small size, but show traces of their origin as a part of the egg. It has been observed by all those who have examined the cleavage of the isolated blastomeres of the sea-urchin that the cleavage is, as a rule, incomplete 1 ). It has been supposed that this incomplete development extended only to the cleavage, but it seems to me very probable that the excentric position of the archenteron in the partial embryos of Toxopnenstes is also the outcome of the unsymmetrical structure of the blastomeres. The rapid development of the embryo in this form - gastrulation beginning in warm weather within fifteen hours after fertilization may in part account for the result. The excentric position of the archenteron in this case seems to be similar to that found in the formation of the sstomach " in the etenophore egg as described by Driesce and Morgan.

Boveri's recent study ${ }^{2}$ of the egg of Strongylocentrotus lividus has shown that the micromere pole lies opposite to the position taken by the segmentation nucleus - - a fact that Whimman and I had also observed in 1894. BoverI has also shown that the whole micromere hemisphere is invaginated to form the archenteron. Driesch's results had already made it highly probable that the archenteric pole is the micromere pole, and Boveri's results make this certain. Boverr states that although his results show that there is a definite relation between the parts of the egg and the gastrula, yet his own observations (as do also those of DrIesch and myself) show that while this may be true yet pieces of the egg may still

1) Except in one case in Toxopneustes described by E. B. WILson in which total cleavage was observed.

2) Verhandl. d. phys.-med. Gesellsch. zu Würzburg. N. F. XXXIV. 1901. Arehiv f. Entwickelungsmechanik. XIm. 
gastrulate that have come from the hemisphere that is opposite the micromere pole. We see then that even in cases with a perfectly definite type of clearage that give rise to embryos having definite relations to this cleavage there is no absolntely necessary relation between the two, for if the conditions are changed the relation may also be altered or at least parts of the egg may invaginate that do not do so under ordinary eircumstances. Nevertheless the pre-existing protoplasmic relations in the segmenting egg appear to have an important influence on the formation of the normal embryo, and such a relation accounts for, I think, the excentric position of the archenteron in the $1 / 2$ and $1 / 4$ embryos of Toxopneustes.

\section{Summary.}

1) Those $1 / 2$ and $1 / 4$ embryos of Toxopneustes variegatus that gastrulate at nearly same time as do the whole embryos invaginate about one half and one fourth the number of cells invaginated by the whole embryos.

2) Those $1 / 2$ and $1 / 4$ and $1 / 8$ embryos, that gastrulate later than the whole embryos, invaginate proportionately a larger number of cells. The explanation of this is that the number of cells slowly increases in the partial blastulae so that those that gastrulate late turn in more cells than those that gastrulate early.

3) The size of the archenteron in the late partial embryos, especially in the $1 / 4$ and $1 / \mathrm{s}$ embryos, is generally proportionately larger than in the whole embryos.

4) The archenteron in the $1 / 2$ and $1 / 4$ embryos is excentric in position which seems to be due to the unsymmetrical organisation of the isolated blastomere.

5) The number of cells invaginated in late gastrulae and, in general, in the late smallest gastrulae, as compared with the number in the outer wall is greater in the partial embryos than in whole embryos.

\section{Zusammenfassung,}

1) Diejenigen Halb- und Viertelembryonen von Toxopneustes variegatus, welche die Gastrula ann:ahernd zur selben Zeit bilden wie die ganzen Embryonen, stiulpen etwa die Hailfte oder ein Viertel der Zellenanzahl ein wie die ganzen Embryonen. 
2) Diejenigen Halb-, Viertel- nud auch Achtelembryonen, welche die Gastrula später als die ganzen Embryonen bilden, stiilpen eine verhältnismäßig größere Zahl von Zellen ein. Es erklärt sich das aus dem allmählichen Wachsthum der Zellenanzahl in den Theilblastulae, so dass die spät die Gastrula bildenden mehr Zellen einstiilpen als die frühzeitig gastrulirenden.

3) Die Größe des Urdarmes in den Theilembryonen, speciell in den Viertelund Achtelembryonen, ist in der Regel verhältnismäßig bedentender als in den ganzen Embryonen.

4) Der Urdarm in den Halb- und Viertelembryonen besitzt eine excentrische Lage, welche von der unsymmetrischen Organisation der isolirten Blastomeren herzuruihren scheint.

5) Die Anzahl der eingestuilpten Zellen bei den spät gebildeten Gastrulae und im Allgemeinen bei den kleinsten Gastrulae ist im Vergleich mit der Zellenzahl der Außenwand in den Theilembryonen größer als in den Ganzembryonen. 